\title{
Tulane
}

\author{
Tulane Economics Working Paper Series
}

\section{Measuring, Explaining, and Controlling Tax Evasion: Lessons from Theory, Experiments, and Field Studies}

\author{
James Alm \\ Department of Economics \\ Tulane University \\ New Orleans, LA \\ jalm@tulane.edu
}

Working Paper 1213

July 2012

\begin{abstract}
In this paper, I assess what we have learned about tax evasion since Michael Allingham and Agnar Sandmo launched the modern analysis of tax evasion in 1972. I focus on three specific questions and the answers to these questions that have emerged over the years. First, how do we measure the extent of evasion? Second, how can we explain these patterns of behavior? Third, how can we use these insights to control evasion? In the process, I illustrate my own answers to these questions by highlighting various specific examples of research. My main conclusion is that we have learned many things but that we also still have many gaps in our understanding of how to measure, explain, and control tax evasion. I also give some suggestions and some predictions about where promising avenues of future research may lie.
\end{abstract}

Keywords: Tax evasion, behavioral economics, experimental economics JEL: H2, H26, D03, C9 


\title{
Measuring, explaining, and controlling tax evasion: Lessons from theory, experiments, and field studies
}

\author{
James Alm*
}

\begin{abstract}
In this paper, I assess what we have learned about tax evasion since Michael Allingham and Agnar Sandmo launched the modern analysis of tax evasion in 1972. I focus on three specific questions and the answers to these questions that have emerged over the years. First, how do we measure the extent of evasion? Second, how can we explain these patterns of behavior? Third, how can we use these insights to control evasion? In the process, I illustrate my own answers to these questions by highlighting various specific examples of research. My main conclusion is that we have learned many things but that we also still have many gaps in our understanding of how to measure, explain, and control tax evasion. I also give some suggestions - and some predictions - about where promising avenues of future research may lie.
\end{abstract}

Keywords Tax evasion, behavioral economics, experimental economics.

JEL Classifications H2, H26, D03, C9.

* Department of Economics, Tulane University, 6823 St. Charles Avenue, 208 Tilton Hall, New Orleans, LA 70118-5698 (telephone +1 504862 8344; fax +1 504865 5869; email jalm@tulane.edu). This paper is based on my keynote address at the $66^{\text {th }}$ Annual Congress of the International Institute of Public Finance (IIPF), "Tax Evasion, Tax Avoidance, and the Shadow Economy", held at Uppsala University in Uppsala, Sweden in August 2010. I am greatly indebted to Friedrich Schneider for many helpful discussions. 


\section{Introduction}

It is routinely - and correctly - said that work on tax evasion has expanded enormously since its first systematic theoretical analysis by Allingham and Sandmo (1972). ${ }^{1}$ Given the explosion in this work, a natural question to ask now is: what do we really know about tax evasion? In this paper, I give my own answer to this broad question, by answering several other, more specific, questions. First, how do we measure the extent of evasion, given that it represents behavior that by its very nature individuals and firms go to some length to hide? Second, how can we explain these patterns of behavior, via theoretical, empirical, and experimental methods? Third, how can we use these various insights to control evasion? In the process, I illustrate my answers to these questions by highlighting various specific examples of research. My main conclusion is that we have learned much in the last 40 years but that we also have many gaps in our understanding of how to measure, explain, and control tax evasion. I also give some suggestions - and some predictions - about where promising avenues of future research may lie.

\section{Measuring evasion}

A fundamental difficulty in analyzing tax evasion is the lack of reliable information on taxpayer compliance. After all, tax evasion is illegal, and individuals have strong incentives to conceal their cheating, given financial and other penalties that are imposed on individuals who are found cheating on their taxes. There have been many approaches to measurement, which I broadly classify as Traditional and Modern. I include among Traditional methods "direct",

\footnotetext{
${ }^{1}$ See Cowell (1990), Andreoni, Erard, and Feinstein (1998), Slemrod and Yitzhaki (2002), Sandmo (2005), Slemrod (2007), and Torgler (2007) for comprehensive surveys and assessments of the evasion literature.
} 
"indirect", and "model" approaches. I also discuss a variety of Modern methods that defy a neat classification and that illustrate the creativity that researchers are applying to measurement issues. Box 1 illustrates some of these methods, using examples from my own research.

\subsection{Traditional approaches ${ }^{2}$}

Among traditional approaches, the most accurate source of information on individual compliance is based on "direct" measurement of evasion via actual audits of individual returns. For example, from 1965 to 1988, the U.S. Internal Revenue Service (IRS) conducted detailed line-by-line audits of a stratified random sample of roughly 50,000 individual tax returns on a 3year cycle via its Taxpayer Compliance Measurement Program (TCMP). These audits yielded an IRS estimate of the taxpayer's "true" income, which when compared to actual reported items allowed the IRS to calculate measures of income tax evasion (e.g. the "tax gap"). The TCMP has now been replaced by the National Research Program (NRP), which examined roughly 46,000 randomly selected individual returns for the year 2001 (but only some of which were subject to line-by-line audits). NRP data are now being analyzed in detail. Few other countries have systematic audit-based programs.

Another direct approach is based on survey evidence, in which individuals are asked about their evasion behavior. Still another direct approach uses tax amnesty data, in which declarations of income by amnesty participants are used as an exact measure of evasion.

More "indirect" methods look for traces of evasion behavior that are left in various indicators that can be identified, so that evasion is not measured directly but rather indirectly via these measureable traces. There are several indicators that have often been used. One approach

\footnotetext{
${ }^{2}$ See Schneider and Enste $(2000,2002)$ and Schneider (2005) for detailed discussions and critiques of these approaches.
} 
estimates evasion via some "gap" that can be estimated, such as the gap between income reported on tax returns and income in the national income accounts, between income and expenditures in the national income accounts, or between official and actual labor forces.

Another indirect approach looks for traces of evasion in transactions financed by currency, on the assumption that the "true" level of economic activity can be estimated via a Fisherian relationship between money and its velocity. The gap between this predicted level of economic activity and the official national accounts level gives a measure of the so-called "shadow economy", which can then used as a proxy for the amount of tax evasion. ${ }^{3}$ A related and more commonly used method is the currency demand approach, which estimates the demand for currency as a function of conventional factors (e.g., income, interest rates) and also as a function of factors that are assumed to motivate individuals to engage in evasion activities (e.g., the direct and indirect tax burden, government regulation, the complexity of the tax system). Any "excess" in currency demand, or the amount unexplained by the explanatory variables, is then attributed to the shadow economy and, by extension, the amount of tax evasion.

Another related indirect approach assumes that there is a constant relationship between some physical input like electricity consumption and "true" economic activity; by measuring the gap between the official output and the predicted "true" economic activity from the physical input, the amount of tax evasion can again be estimated.

\footnotetext{
${ }^{3}$ A common definition of the shadow economy is that it includes all economic activities that contribute to the officially calculated gross national (or domestic) product but that are not included in these accounts. Relatedly, the shadow economy could be defined as all market-based but unreported income from the production of legal goods and services, either from monetary or barter transactions, which would normally be taxable if they were reported to the tax authorities. Other definitions are of course possible. A particularly useful formulation by Schneider (2005) defines the shadow economy as all market-based legal production of goods and services that are deliberately concealed from public authorities to avoid payment of income, value added or other taxes, to avoid payment of social security contributions, to avoid certain legal labor market standards (e.g., minimum wages, safety standards), or to avoid certain administrative procedures (e.g., completing statistical questionnaires).
} 
These indirect methods consider just one indicator that is assumed to capture all effects driving the shadow economy and/or tax evasion. However, shadow economy effects may show up simultaneously in multiple markets (e.g., production, labor, and money markets). The "model" approach explicitly incorporates multiple causes leading to the shadow economy, as well as the multiple effects of the shadow economy over time. This approach is based on the statistical theory of unobserved variables, which considers multiple causes and multiple indicators of the phenomenon to be measured. The "DYMIMIC" (or "Dynamic Multiple Indicators - Multiple Causes") model exploits this theory, and consists in general of two parts. A measurement model links the unobserved variables to observed indicators; a structural equation model then specifies causal relationships among the unobserved variables.

As discussed in detail by Schneider and Enste (2000, 2002) and Schneider (2005), all of these direct, indirect, and model methods are subject to criticism. For example, TCMP/NRP data have some well-recognized deficiencies, even aside from their expense: the audits do not detect all underreported income, nonfilers are not often captured, honest errors are not identified, and final audit adjustments are not included. Survey data often have much useful sociodemographic and taxpayer attitudinal information, but the reliability of their data on tax evasion highly suspect because individuals may not remember their reporting decisions, they may not respond truthfully or at all, and the respondents may not be representative of all taxpayers. Amnesty data may also not be representative of all taxpayers because only some individuals opt to participate in an amnesty. The many indirect approaches also exhibit problems. For example, the various "gap" estimates attribute any discrepancy to the shadow economy and/or to tax evasion. The currency demand or transactions approaches require a base year in which there is a zero shadow economy, a value for monetary velocity, and a precise estimate of the total volume of financial 
transactions; they also attribute any difference between predicted and actual transactions to the shadow economy. All of these assumptions are problematic. Even the sophisticated DYMIMIC approach faces difficult endogeneity and causation issues in its two-stage estimation procedure. Perhaps because of these difficulties, researchers have turned increasingly to alternative approaches.

\subsection{Modern approaches}

More recent approaches use a variety of novel methods. Some researchers have used measures of reported income from individual tax returns as a proxy for evasion, on the assumption that one's total income must be divided between reported income and unreported (or evaded) income (e.g., Dubin, Graetz, and Wilde, 1990; Gruber and Saez, 2002). ${ }^{4}$ Other researchers have conducted controlled field experiments (Slemrod, Blumenthal, and Christian, 2001; Iyer, Reckers, and Sanders 2010; Kleven et al., 2010). Some have used consumptionbased (Pissardes and Weber, 1989) or tax deduction-based (Feldman and Slemrod, 2007) measures as an indicator of tax evasion. There are also examples of survey-based approaches in which particular occupations are examined to determine individual motivations to participate in the shadow economy (Lemieux, Fortin, and Frechette, 1994; DePaula and Scheinkman, 2010). All of these studies lack direct measures of evasion.

There are numerous examples of even more novel approaches. Researchers have used luminosity as measured from outer space to measure "true" economic activity, which can be compared to official income accounts to measure evasion (Henderson, Storeygard, and Weil,

\footnotetext{
${ }^{4}$ Note that reported income is not simply the mirror image of evaded income because it reflects factors that affect a wide range of individual choices beyond tax evasion (e.g., labor supply, savings, compensation form, hours worked, labor force participation, employee compensation, itemized deductions, savings in tax-preferred accounts, income realizations, tax shelter and other tax avoidance mechanisms, taxable form).
} 
2009). Still others have collected their own compliance data from original sources, such as information on cigarette tax evasion using discarded cigarette packs to measure the degree to which smokers in a single jurisdiction (e.g., Chicago, New York City) evaded the jurisdiction's cigarette taxes (Chernick and Merriman, 2009).

Box 1 illustrates some of these methods, using examples from my own research.

\section{Explaining evasion}

Attempts to explain tax evasion rely on conventional tools of theoretical, empirical, and experimental methods. In this section I discuss insights from each approach.

\subsection{Using theory}

\subsubsection{The Allingham and Sandmo "portfolio" model}

The basic theoretical model used in nearly all research on tax compliance begins with the economics-of-crime model, first applied to tax compliance by Allingham and Sandmo (1972). Here a rational individual is viewed as maximizing the expected utility of the tax evasion gamble, weighing the benefits of successful cheating against the risky prospect of detection and punishment, and the individual pays taxes because he or she is afraid of getting caught and penalized if he or she does not report all income. This "portfolio" approach gives the plausible and productive result that compliance depends upon audit rates and fine rates. Indeed, the central point of this approach is that an individual pays taxes because of this fear of detection and punishment.

To illustrate this implication more precisely, consider the standard model of tax evasion. In its simplest form, an individual is assumed to receive a fixed amount of income $I$, and must 
choose how much of this income to report to the tax authorities and how much to underreport. The individual pays taxes at rate $t$ on every dollar $R$ of income that is reported, while no taxes are paid on underreported income. However, the individual may be audited with a fixed probability $p$; if audited, then all underreported income is discovered, and the individual must pay a penalty at rate $f$ on each dollar that he or she was supposed to pay in taxes but did not pay. The individual's income $I_{C}$ if caught underreporting equals $I_{C}=I-t R-f[t(I-R)]$, or income less taxes paid on reported income less penalties on unreported taxes; if underreporting is not caught, income $I_{N}$ is $I_{N}=I-t R$, or income less taxes paid on reported income. The individual is assumed to choose reported income to maximize expected utility, or $E U(I)=p U\left(I_{C}\right)+(1-p) U\left(I_{N}\right)$, where $E$ is the expectation operator and utility $U(I)$ is a function only of income. This optimization proceeds using standard methods.

This economics-of-crime approach gives the sensible result that compliance depends upon enforcement. Indeed, it is straightforward to show with comparative statics analysis that declared income increases with an increase either in the probability of detection or in the penalty rate. However, this approach also concludes that an individual pays taxes only because of the economic consequences of detection and punishment. The many extensions of this portfolio approach considerably complicate the theoretical analyses, and generally render clear-cut analytical results impossible. Nevertheless, these extensions retain the basic approach and the basic result: individuals focus exclusively on the financial incentives of the evasion gamble, and individuals pay taxes only because they fear detection and punishment.

However, it is clear to many observers that compliance cannot be explained entirely by such purely financial considerations, especially those generated by the level of enforcement. The percentage of individual income tax returns that are subject to a thorough tax audit is generally 
quite small in most countries, almost always well less than 1 percent of all returns. Similarly, the penalty on even fraudulent evasion seldom exceeds more than the amount of unpaid taxes, and these penalties are infrequently imposed; civil penalties on non-fraudulent evasion are even smaller. A purely economic analysis of the evasion gamble suggests that most rational individuals should either underreport income not subject to source withholding or overclaim deductions not subject to independent verification because it is extremely unlikely that such cheating will be caught and penalized. ${ }^{5}$ However, even in the least compliant countries evasion seldom rises to levels predicted by a purely economic analysis, and in fact there are often substantial numbers of individuals who apparently pay all (or most) of their taxes all (or most) of the time, regardless of the financial incentives they face from the enforcement regime. ${ }^{6}$

The portfolio model of individual compliance behavior therefore implies that rational individuals (especially those whose incomes are not subject to third-party sources of information) should report virtually no income. Although compliance varies significantly across countries (and across taxes) and is often quite low, compliance seldom falls to a level predicted by the standard economic theory of compliance. It seems implausible that government enforcement activities alone can account for these levels of compliance; the basic model is

\footnotetext{
${ }^{5}$ More precisely, suppose that the utility function of the individual is $I_{i}^{1-e} /(1-e)$, where the subscript $i$ refers to the state of the world $(i=C, N)$ and $e$ is a measure of the individual's constant relative risk aversion. Using the definitions of $I_{C}$ and $I_{N}$, the expected utility maximization can then be solved for the optimum amount of reported income $R^{*}$. Now suppose that $R^{*}$ is calculated for specific and realistic values of the various parameters. For example, if $t=0.4$, $f=2, p=0.02$, and $e=1$, then the individual will optimally report no income. Very large values for relative risk aversion are required to generate compliance consistent with actual country experience. When $e=3$, reported income is only 14 percent of true income; when $e=5$, it is still only 44 percent; when $e=10$, it is 71 percent. Risk aversion must exceed 30 for compliance to exceed 90 percent. However, existing field evidence on the coefficient of relative risk aversion suggests that $e$ ranges between 1 and 2. Indeed, the (interior) condition for some positive amount of evasion is simply $f<1 / p$. Given that the total fine rate seldom exceeds payment of unpaid taxes plus an additional penalty of unpaid taxes, implying that $f$ equals at most about 2 , this condition will be met for any audit rate that is less than about 50 percent. This condition is also independent of preferences, so different degrees of risk aversion do not change this condition.

${ }^{6}$ For a somewhat contrary view, see Slemrod (2007).
} 
certainly unable to explain this behavior. Indeed, the puzzle of tax compliance behavior may well be why people pay taxes, not why they evade them.

Another troubling feature of the portfolio approach is that it typically predicts that an increase in the tax rate $t$ has an ambiguous and, most likely, a positive effect on reported income. A higher tax rate increases the return to cheating, which reduces reported income via a substitution effect. However, a higher tax rate also has an income effect, and, if the individual exhibits decreasing absolute risk aversion, then lower income makes the evasion gamble less attractive. In fact, when the penalty is imposed at a proportional rate on evaded taxes, as is typically the case in most countries, Yitzhaki (1974) has shown that the substitution effect disappears, so that a higher tax rate will increase reported income via the income effect. As discussed later, this prediction is often at odds with actual evidence.

Finally, although the Allingham and Sandmo (1972) model is elegant in its simplicity, many potentially relevant factors are necessarily omitted. The compliance decision seems likely to be affected by considerations not captured by the basic economics-of-crime approach.

These limitations have led researchers to expand the basic model, in a search for other factors that may better explain why people pay taxes, that may reverse the troubling comparative statics results, and that may add to the realism of the analysis.

\subsubsection{Some extensions}

Many of the theoretical extensions have occurred within the basic economics-of-crime approach, thereby keeping a reliance on expected utility theory. These extensions are discussed in detail by Cowell (1990), Andreoni, Erard, and Feinstein (1998), Slemrod and Yitzhaki (2002), Sandmo (2005), Slemrod (2007), and Torgler (2007), and include: expanding individual choices (e.g., labor supply occupational choice, sectoral choice, avoidance strategies); introducing 
alternative penalty, tax, and tax withholding functions; incorporating complexity and uncertainty about the relevant fiscal parameters; allowing the use of paid preparers; recognizing the provision of government services; giving individuals positive rewards for honesty; and allowing systematic audit selection rules in which the tax authority uses information from the tax returns to determine strategically whom to audit.

These extensions add necessary realism to the basic model. However, they also complicate considerably the comparative statics of the compliance choice. Even so, they leave enforcement as the main factor that motivates compliance, and they do not change the compliance-tax rate response.

There has also been some work to expand the basic model of individual choice beyond the basic economics-of-crime approach, by introducing some aspects of behavior considered explicitly by other social sciences. Many of these can be discussed under the rubric of "behavioral economics", broadly defined as an approach that uses methods and evidence from other social sciences (especially psychology) to inform the analysis of individual and group decision making. I include here models based both on "non-expected utility theory" and on "social interactions theory", recognizing that these strands overlap considerably.

The underlying motivation for the introduction of behavioral economics insights is dissatisfaction with the standard economic approach to analyzing individual behavior. There is now much evidence that, contrary to the standard neoclassical approach to consumer choices, individuals face limits on their ability to compute (e.g., "bounded rationality", "mental accounting"); they systematically misperceive, or do not perceive at all, the true costs of actions (e.g., "fiscal illusion", "saliency", "overweighting" of probabilities); they face limits on their "self-control” (e.g., "hyperbolic discounting", "Christmas savings clubs", "automatic enrollment 
programs"); they are affected by the ways in which choices are "framed" (e.g., reference points, gains versus losses, loss aversion, risk-seeking behavior); they are influenced by the social context in which, and the process by which, decisions are made; and they are motivated not simply by self-interest but also by group notions like social norms, social customs, fairness, trust, reciprocity, tax morale, and even patriotism, as well as by individual notions of guilt, shame, morality, altruism, or alienation. In short, individuals are not always the rational, outcomeoriented, self-controlled, selfish, and egoistic consumers envisioned by much of our standard theory. Behavioral economics uses these so-called "departures" from the standard assumptions as the starting point for developing formal - and more realistic - theories of individual behavior. These theories are now being usefully applied to tax evasion. ${ }^{7}$

One strand of behavioral economics deals mainly with individual behavior, and applies various formalizations of "non-expected utility theory" to these individual choices. One factor that emerges from these efforts is the way in which individuals perceive probabilities. There is overwhelming evidence that individuals "overweight" the low probabilities that they face in tax compliance; that is, even when fully informed, individuals systematically act as if the audit probability that they face is much higher than its actual level. Overweighting of probabilities may therefore provide an additional explanation for tax compliance. If a taxpayer gives more subjective weight to the probability of an audit than implied by its objective level, then compliance will be greater than the level predicted by the standard portfolio approach. More generally, individuals may act on the basis of "subjective probabilities".

Another factor is that many individuals apparently adapt to an unchanged environment

\footnotetext{
${ }^{7}$ For a survey of these theoretical developments as applied to tax evasion, see Myles, Tran-Nam, and Hashimzade (2010). For more general discussions in other areas of behavior, see Camerer, Loewenstein, and Rabin (2004) and McCaffery and Slemrod (2006),
} 
and perceive stimuli relative to this environment. Many individuals react much differently to gains than to (equal-but-opposite valued) losses. Individuals may therefore act on the basis of a "value function" (rather than the utility function in economic models). The value function is assumed to depend upon changes in income from some "reference point", rather than the level of income itself. It is also assumed to be steeper for losses than for gains because a loss in income is disliked much more than an equal gain, and it is concave for gains (risk aversion) but convex for losses (risk seeking), so that an individual may exhibit risk-averse behavior when confronted with risky but positive gambles, while the same individual may become risk-lovers when faced with gambles that involve possible losses.

There are numerous examples of these non-expected utility theories, including (but not limited to): prospect theory, rank dependent expected utility theory, first order and second order risk aversion, regret theory, disappointment theory, non-additive probabilities, and ambiguity theory. For some insightful applications of these approaches, see for example Yaniv (1999), Bernasconi and Zanardi (2004), Snow and Warren (2005), and Dhami and al-Nowaihi (2007). Relative to expected utility theory, these models change the "probability" that an individual perceives and the "objective function" that he or she pursues. In doing so, they considerably complicate the analysis of the individual decision, but they can also generate predicted levels of compliance that better approximate observed levels, especially if they have overweighting of probabilities. However, these models do not typically change the counterintuitive tax rate comparative statics result as long as the payoff to evasion remains based directly on evaded taxes. Changing this result requires that evasion enters payoffs independently of the tax rate. A second strand of behavioral economics focuses more on group behavior, which I classify as the "social interactions theory" strand. For example, there is much evidence of what 
may be termed a "social norm" of tax compliance (Elster, 1989). Although difficult to define precisely, a social norm can be distinguished by the feature that it is process-oriented, unlike the outcome-orientation of individual rationality. A social norm therefore represents a pattern of behavior that is judged in a similar way by others and that therefore is sustained in part by social approval or disapproval. Consequently, if others behave according to some socially accepted mode of behavior, then the individual will behave appropriately; if others do not so behave, then the individual will respond in kind. The presence of a social norm is also consistent with a range of approaches, including those that rely upon social customs, tax morale, appeals to patriotism or conscience, or feelings of altruism, morality, guilt, and alienation. This factor suggests that an individual will comply as long as he or she believes that compliance is the social norm (however defined); conversely, if noncompliance becomes pervasive, then the social norm of compliance disappears. (These norms may also work in part by changing the reference point in the individual's value function.) More broadly, this last factor suggests that the nature of one's social interactions with others affects one's own compliance decision. The presence of a social norm is also consistent with a range of other approaches, including those that rely upon fairness, trust, reciprocity, social customs, tax morale, or patriotism. See Cowell and Gordon (1988), Gordon (1989), Myles and Naylor (1996), Kim (2003), Fortin, Lacroix, and Villeval (2007), and Traxler (2010) for examples of social interactions theory as applied to tax evasion.

These models can generate the "correct" comparative statics responses (mainly because they break the link between evasion and tax rates in payoffs), and they can also give "correct" predictions about the level of compliance if they allow for subjective probabilities. Both of these gains come at the cost of considerable complexity.

\subsection{Using empirical methods}


The empirical analysis of tax evasion obviously requires some measure of noncompliance. As emphasized earlier, such measures are difficult to find and subject to much criticism. However, these limitations have not prevented researchers from attempting to estimate the determinants of evasion, whatever the source of data.

This literature is large and growing, and I can only highlight some important studies. For example, most empirical evidence has found that a higher tax rate generally leads to less compliance, with an estimated underreported income-tax rate elasticity of 0.5 to 3.0 (Clotfelter, 1983; Crane and Nourzad, 1992). Various empirical studies also have found a significant, though diminishing, deterrent effect of higher audit rates, with an estimated reported incomeaudit rate elasticity ranging from 0.1 to 0.2 ; that is, an increase in audit rates of 10 percent increases reported income by 1 to 2 percent (Witte and Woodbury, 1985; Dubin, Graetz, and Wilde, 1990). However, the increase in compliance appears to be nonlinear, which suggests that there are limits to how much government can increase compliance by increasing the probability of detection. Audits also seem to have a "spillover effect", or an increase in compliance independent of revenues generated directly from the audits and penalties themselves (Dubin, 2007). There is substantial evidence that a tax amnesty generates relatively small amounts of additional tax revenues, and seems to have relatively small effects on post-amnesty compliance (Fisher, Goddeeris, and Young, 1989). Similarly, there is strong evidence that audit rates are endogenous, that there are revenue gains from strategic audit selection, and that information sharing across governments could increase compliance (Feinstein, 1991; Alm, Bahl, and Murray, 1993; Johannesen, 2010).

It should be emphasized, again, that this empirical work needs to be treated cautiously. The main difficulty in all empirical work here is the absence of reliable information on 
individual reporting behavior. This information is hard to come by for any country. Also, the information that is available seldom allows the identification of the independent effects of, say, audit rates or fine rates on compliance, given the inevitable commingling of cause-and-effect. These difficulties have not stopped researchers. However, there are obvious problems with the data and with the identification strategy that make much of this empirical work somewhat suspect.

\subsection{Using experimental methods}

Tax compliance is an area that seems especially amenable to laboratory experiments, given limitations in both theoretical and empirical approaches. Theoretical models are not able to incorporate fully, appropriately, or tractably many factors deemed relevant to the individual compliance decision. In a sense, the theory is both too complex and too simple. It is only in the simpler models that clear-cut analytical results can be generated on the compliance impact of basic policy parameters; when more complex dimensions of individual behavior are introduced (including behavioral economics extensions), the theoretical results generally become ambiguous, even intractable. Paradoxically, the theoretical models of individual choice are also too simple. There are numerous factors that affect the reporting decisions of individuals, but theoretical models are capable of including only a few. Empirical studies of tax compliance are plagued by the absence of reliable information on individual compliance decisions, and it is difficult to control in econometric work for the many factors that affect the compliance decision.

In contrast, laboratory methods allow many factors suggested by theory to be introduced in experimental settings. Also, experiments generate precise data on individual compliance decisions, which allow econometric estimation of individual responses in ways that are simply not possible with field data. For example, penalty rates do not vary exogenously across 
individuals, and so it has not been possible to estimate reliably individual responses to changes in penalty rates; independent variation in audit rates across individuals has also proven difficult to generate in natural settings. Examining with field data the impact of other factors often deemed important in compliance decisions (e.g., public good provision, audit selection rules, social processes and institutions) is even more problematic. Indeed, laboratory methods have examined a wide range of factors in the compliance decision, factors that have not proven amenable to either theoretical analyses or empirical analyses with field data. There are some obvious limitations of experimental methods, as I discuss later. However, given the weaknesses of other methodologies, there are some compelling reasons for the use of experiments.

The basic design of most compliance experiments is similar. Human subjects in a controlled laboratory are told that they should feel free to make as much income as possible. At the beginning of each round of the experiment, each subject is given (or earns) income and must decide how much income to report. Taxes are paid at some rate on all reported, but not on underreported, income. However, underreporting is discovered with some probability, and an audited subject must then pay a fine on unpaid taxes. This process is repeated for a given number of rounds. At the completion of the experiment, each subject is paid an amount that depends on his or her performance during the experiment. Into this microeconomic system, various policy changes can be introduced, such as changes in audit probabilities or audit rules, in penalty rates, in tax rates, in public good provision, and in any other relevant institutions.

Virtually all aspects of compliance have been examined in some way in experimental work, starting with Friedland, Maital, and Rutenberg (1978) and extending to subsequent work by Becker, Buchner, and Sleeking (1987), Beck, Davis, and Jung (1990), Webley et al. (1991), and Gerxhani and Schram (2006), among many others. For example, most (but not all) 
experimental studies have found that a higher tax rate leads to less compliance, with an estimated reported income-tax rate elasticity of about 0.5 . A more consistent result across studies is that a higher audit rate leads to more compliance, with an estimated reported income-audit rate elasticity that varies within the narrow range of 0.1 to 0.2 ; this impact appears to be small and nonlinear, so that the deterrent effect of a higher audit rate eventually diminishes. There is also convincing evidence that many subjects appear to substantially overweight the probability of an audit, so that there is far more compliance than is predicted by expected utility theory, a result that is nearly universal across all experimental designs. Most studies have found that compliance increases but only slightly with increases in the fine rate on unpaid taxes, and that public disclosure of non-compliance acts as an additional penalty mechanism. The presence of a public good financed by voluntary tax payments has been found to increase subject tax compliance in a nonlinear manner. Like group rewards, individual rewards (e.g., eligibility for a lottery if an audit indicates full reporting, receipt of social insurance benefits that are conditional upon filing) have been shown to provide a significant positive inducement for greater compliance.

Many other factors have been investigated, such as audit "productivity", withholding systems, audit selection methods, complexity and uncertainty, taxpayer services, social institutions, collective decision rules, notions of "fairness" and "inequity", and tax amnesties. See Torgler (2007) and Alm and Jacobson (2007) for a detailed discussion of these many studies.

There are many reasons for caution in the use and interpretation of experimental economics. Some early compliance experiments did not follow some now widely accepted procedures of the experimental paradigm, such as the use of repeated experiments and neutral instructions. Much early work also lacked realism because values of the various policy parameters did not approximate real-world values. More recent experimental research has 
addressed these problems. Even so, some concerns remain.

A common criticism of experimental economics is that the student subjects typically used may not be representative of taxpayers. However, there is now much evidence that the experimental responses of students are seldom different than the responses of other subject pools. There is also no reason to believe that the cognitive processes of students are different from those of "real" people. A related and more general concern about the subject pool is that the subjects choose voluntarily to participate, thereby introducing potential bias. However, participants in virtually any study - laboratory experiments, controlled field studies, surveys, and the like - are invariably volunteers, and it seems unlikely that laboratory experiments are inordinately affected relative to other approaches.

Another common criticism is that it is not possible to control for many relevant factors in the laboratory. However, if one cannot control for such factors in the laboratory where the experimenter establishes the institutions, the rules, and the reward structure, then one cannot hope to control for these factors in the naturally occurring world.

Of more legitimate concern, the results may well be sensitive to the specific experimental design, so that replication is crucial. It is also possible that subjects may modify their behavior simply because they know that they are participating in an experiment. Most importantly, there is a certain artificiality in any laboratory setting. A decision to report, say, three tokens of income in a tax compliance experiment is clearly different than a decision to report actual income on an annual tax return, even if the laboratory incentives are salient. In particular, the laboratory setting cannot capture a catastrophic loss such as jail, and it cannot capture the social stigma that some surveys suggest is an important factor in taxpayer reporting. Put differently, there are legitimate concerns about the "external validity" of experimental studies of tax 
compliance (Levitt and List, 2007); that is, do the results in the laboratory apply more broadly to the "naturally occurring world"? Of course, this is an issue that every data-driven study must confront, and it cannot be answered in general but must be addressed in each specific case.

\subsection{Summary: What does all of this evidence show?}

Box 2 illustrates some insights from these three approaches, again using examples from my own research. In total, these theoretical, empirical, and experimental studies indicate that individuals respond predictably, if not always significantly, to such factors as higher tax rates, increased audit rates, more "productive" audits, repeated audits, strategic/targeted audit selection, public disclosure of audit, public dissemination of audit information, increased penalty rates, greater use of source-withholding, more use of information-sharing between government audit agencies, greater rewards - public or private - for compliance, a closer taxes-services linkage, increased taxpayer participation in group decisions, tax amnesties, increased complexity and uncertainty, and better taxpayer services.

These results may be expected. Indeed, much of this research tends to confirm one's prior expectations. However, this research also suggests a number of results, which may be somewhat surprising and which I characterize as follows.

First and most importantly, despite the many insights from this research, there remain many unanswered questions. I return to this conclusion later.

Second and more specifically on enforcement measures, audits affect compliance, but with some important qualifications:

- The reported income-audit rate elasticity is often small and varies significantly across studies.

- Audits increase compliance but in a non-linear way, so that the deterrent effect diminishes with higher audit rates. 
- The spillover effect from audits is significantly larger than their direct deterrent.

- Audits have a greater deterrent effect than fines, despite their theoretical equivalence (at least in an expected value sense).

- Strategic audit selection (especially a "cutoff rule") is far better than random selection, but some random selection seems necessary for strategic audit schemes to work.

- The "shadow value" of an auditor - the extra revenue generated from an audit over and above the cost of the audit - often ranges from 3-5.

Third, perceptions of audit rates affect compliance. Indeed, individuals appear to substantially misperceive audit rates, typically overweighting a (low) probability of audit; that is, "psychology" - and other behavioral economics factors - clearly matters. Fourth, fines also affect compliance, but the deterrent effect of fines is quite small, and audits have a significantly greater deterrent effect.

Fifth, aside from enforcement factors, positive rewards improve compliance, whether individual (e.g., lotteries, social insurance benefits) or aggregate (e.g., public goods). Indeed, the "carrot" of rewards is often more effective in encouraging compliance than the "stick" of (equal expected value) enforcement.

Sixth, tax rates affect compliance but in ways that go beyond their simple incentive effects. The level of tax rates matters in an individual's compliance decision, although the magnitude - and even the direction - of impact is unclear. One's tax rate relative to others' (e.g., "fiscal inequity") is a crucial factor. The use of taxes affects compliance, especially when subjects can choose the use. Seventh, this last result suggests that process (versus outcome) affects compliance. Indeed, there seems to be a "social norm" of compliance, and this social norm can be affected by the institutions that face individuals, by individuals' attitudes toward these institutions, and by individual participation in the selection of those institutions. Eighth, tax amnesties affect compliance (possibly through their effects on social norms), but amnesty 
effects seem neither large nor small, neither all that positive nor all that negative.

Ninth, simplicity versus complexity affects compliance (e.g., an increase in complexity increases the probability that an individual will use a "tax practitioner"), but the impact of a complicated tax system on the level of compliance is unresolved. Even so, there is some suggestive evidence that better administrative services can improve compliance.

Finally, there is little question that compliance is affected by multiple factors, beyond the narrow financial considerations of enforcement; that is, there is a "full house" of behaviors motivated by a "full house" of considerations. This last conclusion has important implications for controlling evasion, to which I now turn.

\section{Controlling evasion}

This discussion indicates that there is now much theoretical, empirical, and experimental evidence that individuals respond predictably, if not always significantly, to a range of policies. How can all of this research be used in the design of measures to control tax evasion? I believe that there are three "paradigms" for tax administration that emerge from this research. Box 3 provides examples of, and results from, specific policies suggested by these paradigms.

Tax administration typically emphasizes a variety of measures, including traditional policies such as introducing an effective audit program that identifies individuals who do not file tax returns and those who underreport income or overclaim deductions and credits, applying nonharsh penalties often and consistently, using source-withholding whenever possible, facilitating payments through the banking system, and making use of third-party sources of information to verify reporting behavior. These policies are consistent with a paradigm that views the taxpayer 
as a potential criminal who must be deterred from cheating, and are clearly aligned with the economics-of-crime perspective.

However, it is increasingly the case that administrative policies are not limited to these standard enforcement mechanisms. Instead, tax administrations in many countries are introducing policies that emphasize such things as developing taxpayer services to assist taxpayers in every step of their filing returns and paying taxes, broadcasting advertisements that link taxes with government services, simplifying taxes and the payment of taxes, and even promoting a taxpayer - and a tax administrator - "code of ethics". Put differently, the taxpayer is no longer seen simply as a potential criminal but as a potential client, one whose behavior depends upon his or her moral values. These new policies suggest several additional paradigms for tax compliance beyond the one that emerges from the economics-of-crime analysis, paradigms for which there is now emerging much theoretical, empirical, and experimental support.

Under the first paradigm - the traditional "enforcement paradigm" - the emphasis is exclusively on repression of illegal behavior through frequent audits and stiff penalties. This has been the conventional paradigm of tax administrations throughout history, and it fits well the standard portfolio model of tax evasion based upon the economics-of-crime theory.

A second paradigm recognizes the role of enforcement, but also recognizes the role of tax administration as a facilitator and a provider of services to taxpayer-citizens. This new "service paradigm" for tax administration fits squarely with the perspective that emphasizes the role of government-provided services as considerations in tax compliance; it is also consistent with the view that the government has an incentive both to justify its actions and to convince taxpayers to pay taxes, all with the goal of maintaining power. Indeed, the most recent literature on tax 
administration reform has emphasized this new paradigm of the role of tax administration, as a facilitator and a provider of services to taxpayer-citizens, and many recent administrative reforms around the world have embraced this new paradigm with great success.

A third paradigm is also suggested by this work, especially the work that demonstrates the importance of ethics in tax compliance behavior. I term this a "trust paradigm", and it is consistent with the role of morality, of social norms, and of other behavioral economics factors in the compliance decision. ${ }^{8}$

Given this discussion, designing strategies to control tax evasion fall into three main categories, each consistent with one of the three paradigms: increase the likelihood and the threat of punishment, improve the provision of tax services, and change the tax culture.

$\underline{\text { First }}$, there is scope for an improvement in policies to increase detection and punishment (e.g., the "enforcement paradigm"). Traditionally, there are three main aspects of tax administration: taxpayer registration, taxpayer audit, and collections. Improvements in each of these areas are feasible, all of which would enhance detection and punishment. These policies includes such obvious actions as increasing the number of audits, improving the quality of the audits (and of the auditors), using more systematic audit selection methods (e.g., "scoring" methods), improving information-sharing across governments, increasing penalties for tax cheating, publicizing tax evasion convictions in the media as an alternative non-financial type of

\footnotetext{
${ }^{8}$ This "trust paradigm" is reflected in a range of slightly different but clearly related administrative approaches, with roots in the psychology of taxation (Lewis, 1982; Kirchler, 2007). For example, Kirchler, Hoelzl, and Wahl (2008) explore the interaction between enforcement effort ("power") and facilitation ("trust") on the part of the tax authority via a "slippery slope" framework. McBarnet (2004) suggests that people may choose to comply willingly (what she terms "committed compliance"), they may choose to comply unwillingly ("capitulative compliance"), they may take full advantage of the law in minimizing their taxes ("creative compliance"), or they may choose noncompliance; appropriate enforcement policies vary with the motivation. Similarly, Braithwaite (2009) argues that individuals are motivated either by "deference" motives or by "defiance" motives, and that enforcement actions should be tailored to reflect these different motivations. Also, Frey (1997) discusses how one's "intrinsic motivation" to obey the law may be crowded out by enforcement actions.
} 
penalty, applying penalties often and consistently, relying more heavily on source-withholding, granting additional power for collecting delinquent accounts, and increasing taxpayer registration and identification via better use of third-party information. These are all standard methods for increasing enforcement.

Second, there is scope for an improvement in the services of the tax administration by becoming more "consumer-friendly", along the lines of the "service paradigm". Such policies include promoting taxpayer education, providing taxpayer services to assist taxpayers in filing returns and paying taxes, improving phone advice service, improving the tax agency website, simplifying taxes and tax forms, and simplifying the payment of taxes. The basic thrust of these "service paradigm" actions is to treat the taxpayer more as a client than as a potential criminal.

Third, there may be scope for a governmental-induced change in the culture of paying

taxes, consistent with the "trust paradigm", by using the mass media to reinforce tax compliance as the ethical form of behavior, publicizing cheaters, emphasizing the link between payment of taxes and the receipt of government services, targeting certain groups (e.g., new firms or employees) in order to introduce from the start the notion that paying taxes is "the right thing to do", enlisting other organizations to promote compliance, avoiding actions that lead individuals to think cheating is "okay" (e.g., a tax amnesty), and addressing perceived inequities in the ways people feel that they are treated. It is this third paradigm that is, I believe, an essential but largely neglected strategy for improving compliance.

\section{Conclusions}

My basic conclusion is a simple one: we have learned a lot in the last 40 years but there 
are still major gaps in our understanding. Indeed, we are still trying to answer many basic questions on measuring, explaining, and controlling evasion, questions that require much additional research. How much evasion really occurs - nationally and locally? Do higher tax rates encourage/discourage compliance? How effective are penalty rates? What about audit rates - and targeted, announced audit programs? What is the actual magnitude of any individual response? What are costs versus benefits of policies? What are distributional effects of evasion, and of policies to reduce evasion? ${ }^{9}$

There are also many fundamental frontier questions where we have some evidence but evidence that is far from conclusive. How does the presence of taxpayer uncertainty about either taxable income or the various administrative parameters (e.g., the audit rate or the fine rate) affect compliance? Can individuals "coordinate" their compliance decisions? Does tax simplification contribute to more tax compliance? Can better tax agency services improve taxpayer compliance? Can positive inducements (e.g., social insurance programs, lotteries) improve compliance? How is compliance affected by the use of tax revenues and by the collective decision process by which these uses are chosen? How do other societal institutions and social processes affect tax compliance? Do perceptions of "fiscal inequity" affect compliance? What is the role of social norms (or related notions) in compliance? When do psychological factors work/fail, and can government "exploit" these factors? How can social

\footnotetext{
${ }^{9}$ Even on the narrow issue of the effectiveness of audits, there are many unanswered questions. Does greater enforcement increase compliance, or does it destroy "trust" in government and crowd out "intrinsic motivation"? Does public disclosure of audit results act as a non-financial deterrent? Is compliance affected by the "cost" financial or emotional - that an audit imposes on taxpayers? Can more effective strategic audit selection methods be designed? Are random audits necessary to ensure the effectiveness of targeted audit schemes? How can non-filers be audited, or even reached, by tax administration? How do individuals respond when the "productivity" (or the efficiency) of an audit varies? How is information about enforcement disseminated among taxpayers, and how do taxpayers respond to this information? How is group compliance affected when some individuals face a "certain" probability of audit and others are informed that they will not be audited? How do individuals - or firms - respond when they are told that they face an audit?
} 
norms be affected by deliberately chosen government policies? What are the social dynamics of compliance, and how can these dynamics be affected by government policies? What about businesses? What about other taxes (e.g., sales taxes, value added taxes, corporate income taxes)? Theoretical, empirical, and experimental methods (including controlled field experiments) must be applied to these and many other questions before we are better able to understand evasion.

I conclude with five predictions about the direction of future research. First, theory is essential, and new theories will continue to be developed. However, I believe that there will be growing recognition and acceptance that one theory may not fit all individuals at all times, or even the same individual at different times. Individuals in their infinite variety exhibit a "full house" of behaviors, behaviors that cannot be neatly captured by a single methodology.

Second, these new theories will be largely outside the mainstream of economics and indeed will move beyond psychology to sociology, anthropology, and other social sciences in order to understand better which features of naturally occurring settings are likely to affect individual and group decisions. For example, the notion of "reciprocity" arises in large part from anthropology, and that of "adherence to group norms" from sociology. Using alternative perspectives on human behavior cannot help but expand our understanding of individual behavior, as demonstrated most clearly in Akerlof and Kranton (2000) and Akerlof and Shiller (2009).

Third, the focus will shift away from modeling individual behavior to modeling group behavior, including the evolution over time of aggregate behavior. Such aggregate behavior will necessarily be forced to consider taxes beyond the individual income tax (including especially taxes on internationally mobile firms and factors), and "agent-based models" will emerge as a 
leading tool here.

Fourth, laboratory experiments will play a decisive role in developing and testing these

theories. Fifth and finally, there will be an increased emphasis on controlled field experiments to study compliance. An especially promising issue for field experiments is, I believe, tax simplification.

In short, these "predictions" involve using theory, empirics, and experiments: there should be a "full house" of strategies to measure, explain, and control the "full house" of behaviors and motivations.

\section{References}

Akerlof, G. A., \&Kranton, R. E. (2000). Economics and identity. The Quarterly Journal of Economics, 115 (3), 715-753.

Akerlof, G. A., \& Shiller, R. J. (2009). Animal Spirits: How Human Psychology Drives the Economy and Why It Matters. Princeton, NJ: Princeton University Press.

Allingham, M. G., \& Sandmo, A. (1972). Income tax evasion: A theoretical analysis. Journal of Public Economics, 1 (3-4), 323-338.

Alm, J. (1987). Uncertain tax policies, individual behavior, and welfare. The American Economic Review, 78 (1), 237-245.

Alm, J., Bahl, R., \& Murray, M. N. (1990). Tax structure and tax compliance. The Review of Economics and Statistics, 72 (4), 603-613.

Alm, J., Bahl, R., \& Murray, M. N. (1991). Tax base erosion in developing countries. Economic Development and Cultural Change, 39 (4), 849-872.

Alm, J., Bahl, R., \& Murray, M. N. (1993). Audit selection and income tax underreporting in the tax compliance game. Journal of Development Economics, 42 (1), 1-33.

Alm, J., Bloomquist, K., \& McKee, M. (2010). On the external validity of tax compliance experiments. Tulane University Working Paper. New Orleans, LA.

Alm, J., Cherry, T., Jones, M., \& McKee, M. (2010). Taxpayer information assistance services and tax reporting behavior. Journal of Economic Psychology, 31 (4), 577-586.

Alm, J., \& Embaye, A. (2010). Using panel methods to estimate shadow economies around the world, 1984-1986. Andrew Young School of Policy Studies Working Paper. Atlanta, GA.

Alm, J., Jackson, B. R., \& McKee, M. (1993). Fiscal exchange, collective decision institutions, and tax compliance. Journal of Economic Behavior and Organization, 22 (4), 285-303.

Alm, J., \& Jacobson, S. (2007). Using laboratory experiments in public economics. National Tax Journal, 60 (1), 129-152. 
Alm, J., \& Melnik, M. I. (2010). Do eBay sellers comply with state sales taxes? National Tax Journal, 63 (2), 215-236.

Alm, J., \& Yunus, M. (2009). Spatiality and persistence in U.S. individual income tax compliance. National Tax Journal, 62 (1), 101-124.

Andreoni, J., Erard, B., \& Feinstein, J. (1998). Tax compliance. The Journal of Economic Literature, 36 (2), 818-860.

Beck, P. J., Davis, J. S., and Jung, W. (1991). Experimental evidence on taxpayer reporting behavior. The Accounting Review, 66 (3), 535-558.

Becker, W., Buchner, H., \& Sleeking, S. (1987). The impact of public transfer expenditures on tax evasion: An experimental approach. Journal of Public Economics, 34 (2), 243-252.

Bernasconi, $M$ and Zanardi, A. (2004). Tax evasion, tax rates and reference dependence. FinanzArchiv, 60 (4), 422-445.

Braithwaite, V. (2009). Defiance in Taxation and Governance - Resisting and Dismissing Authority in a Democracy. Cheltenham, UK and Northhampton, MA: Edward Elgar Publishing.

Camerer, C. F., Loewenstein, G. F., \& Rabin, M. (Eds.) (2004). Advances in Behavioral Economics. Princeton, NJ: Russell Sage Foundation and Princeton University Press.

Chernick, H., \& Merriman, D. (2009). Using littered pack data to estimate cigarette tax avoidance in NYC. CUNY Working Paper. New York, NY.

Clotfelter, C. T. (1983). Tax evasion and tax rates: An analysis of individual returns. The Review of Economics and Statistics, 65 (3), 363-373.

Cowell, F. A. (1990). Cheating the Government: The Economics of Evasion. Cambridge, MA: The MIT Press.

Cowell, F. A., \& Gordon, J. P. F. (1988). Unwillingness to pay. Journal of Public Economics, 36 (3), 305-321.

Crane, S. E., \& Nourzad, F. (1992). Analyzing income tax evasion using amnesty data with selfselection correction: The case of the Michigan tax amnesty program. In J. Slemrod (Ed.), Why People Pay Taxes (pp. 167-189). Ann Arbor, MI: University of Michigan Press.

DePaula, R., \& Schneider, J. (2010). The informal sector: An equilibrium model and some evidence from Brazil. Penn Institute for Economic Research Working Paper 10-024. Philadelphia, PA.

Dhami, S., \& al-Nowaihi, A. (2007). Why do people pay taxes? Prospect theory versus expected utility theory. Journal of Economic Behavior and Organization, 64 (1), 171-192.

Dubin, J. A. (2007). Criminal investigation enforcement activities and taxpayer noncompliance. Public Finance Review, 35 (4), 500-529.

Dubin, J. A., Graetz, M. J., \& Wilde, L. L. (1990). The effect of audit rates on the federal individual income tax, 1977-1986. National Tax Journal, 43 (4), 395-409.

Elster, Jon (1989). The Cement of Society - A Study of Social Order. Cambridge, UK: Cambridge University Press.

Feinstein, J. (1991). An econometric model of income tax evasion and its detection. RAND Journal of Economics, 22 (1), 14-35.

Feldman, N., \& Slemrod, J. (2007). Estimating tax compliance with evidence from unaudited tax returns. The Economic Journal, 117 (518), 327-352.

Fisher, R. C., Goddeeris, J. H., \& Young, J. C. (1989). Participation in tax amnesties: The individual income tax. National Tax Journal, 42 (1): 15-27. 
Fortin, B., G. Lacroix, and M.-C. Villeval (2007). Tax evasion and social interactions. Journal of Public Economics, 91 (8), 2089-2112.

Frey, B. (1997). Not Just For the Money - An Economic Theory of Personal Motivation. Cheltenham, United Kingdom: Edward Elgar Publishing Limited.

Friedland, N., Maital, S., \& Rutenberg, A. (1978). A simulation study of income tax evasion. Journal of Public Economics, 10 (1), 107-116.

Gerxhani, K., \& Schram, A. (2006). Tax evasion and income source: A comparative experimental study. Journal of Economic Psychology, 27 (3), 402-422.

Gordon, J. P. F. (1989). Individual morality and reputation costs as deterrents to tax evasion. European Economic Review, 33 (4), 797-805.

Gruber, J., \& Saez, E. (2002). The elasticity of taxable income: Evidence and implications. Journal of Public Economics, 84 (1), 1-32.

Henderson, J. V., Storeygard, A., \& Weil, D. N. (2009). Measuring economic growth from outer space. NBER Working Paper 15199. Cambridge, MA.

Iyer, G. S., Reckers, P. M. J., \& Sanders, D. L. (2010). Increasing tax compliance in Washington state: A field experiment. National Tax Journal, 63 (1), 7-32.

Johannesen, N. (2010). Tax evasion and Swiss bank accounts. University of Copenhagen Working Paper. Copenhagen, Denmark.

Kim, Y. (2003). Income distribution and equilibrium multiplicity in a stigma-based model of tax evasion. Journal of Public Economics, 87 (9), 1591-1616.

Kirchler, E. (2007). The Economic Psychology of Tax Behavior. Cambridge, UK: Cambridge University Press.

Kirchler, E., Hoelzl, E., \& Wahl, I. (2008). Enforced versus voluntary tax compliance: The "slippery slope" framework. Journal of Economic Psychology, 29 (2), 210-225.

Kleven, H. J., Knudsen, M. B., Kreiner, K. T., Pedersen, S., \& Saez, E. (2010). Unwilling or unable to cheat? Evidence from a randomized tax audit experiment in Denmark. NBER Working Paper 15769. Cambridge, MA.

LeMieux, T., Fortin, B., \& Frechette, P. (1994). The effect of taxes on labor supply in the underground economy. The American Economic Review, 84 (1), 231-254.

Lewis, A. (1982). The Psychology of Taxation. Oxford, UK: Martin Robertson.

Levitt, S. D., \& List, J. A. (2007). What do laboratory experiments tell us about the real world? The Journal of Economic Perspectives, 21 (2), 153-174.

McBarnet, D. (2004). Crime, Compliance, and Control. Burlington, VT: Ashgate/Dartmouth Publishers Ltd.

McCaffery, E. J., \& Slemrod, J. (Eds.) (2006). Behavioral Public Finance. New York, NY: Russell Sage Foundation.

Myles, G. D., \& Naylor, R. A. (1996). A model of tax evasion with group conformity and social customs. European Journal of Political Economy, 12 (1), 49 - 66.

Myles, G., Tran-Nam, B., \& Hashimzade, N. (2010). New approaches to the economics of tax evasion. University of Exeter Working Paper. Exeter, UK.

Pissarides, C.A., \& Weber, G. (1989). An expenditure-based estimate of Britain's black economy. Journal of Public Economics, 39 (1), 17-32.

Sandmo, A. (2005). The theory of tax evasion: A retrospective view. National Tax Journal, 58 (4), 643-663.

Schneider, F. (2005). Shadow economies around the world: What do we really know? European 
Journal of Political Economy, 21 (4), 598-642.

Schneider, F., \& Enste, D. H. (2000). Shadow economies: Size, causes, and consequences. The Journal of Economic Literature, 38 (1), 77-114.

Schneider, F., \& Enste, D. H. (2002). The Shadow Economy - An International Survey. Cambridge, MA: Cambridge University Press).

Slemrod, J. (2007). Cheating ourselves: The economics of tax evasion. The Journal of Economic Perspectives, 21 (1), 25-48.

Slemrod, J., Blumenthal, M., \& Christian, C. (2001). Taxpayer response to an increase probability of audit: Evidence from a controlled field experiment in Minnesota. Journal of Public Economics, 79 (3), 455-483.

Slemrod, J., \& Yitzhaki, S. (2002). Tax avoidance, evasion, and administration. In A. J. Auerbach \& M. Feldstein (Eds.), Handbook of Public Economics (pp. 1423-1470). Amsterdam, London, and New York: Elsevier.

Snow, A., \& Warren, R. S., Jr. (2005). Ambiguity about audit probability, tax compliance, and taxpayer welfare. Economic Inquiry, 43 (4), 865-871.

Torgler, B. (2007). Tax Compliance and Tax Morale: A Theoretical and Empirical Analysis. Cheltenham, UK: Edward Elgar Publishing.

Traxler, C. (2010). Social corms and conditional cooperative taxpayers. European Journal of Political Economy, 26 (1), 89-103.

Webley, P., Robben, P., Elffers, H., \& Hessing, D. (1991). Tax Evasion: An Experimental Approach. Cambridge, UK: Cambridge University Press.

Witte, A. D., \& Woodbury, D. F. (1985). The effect of tax laws and tax administration on tax compliance. National Tax Journal, 38 (1), 1-13.

Yaniv, G. (1999). Tax compliance and advanced tax payments: A prospect theory analysis. National Tax Journal, 52 (4), 753-764.

Yitzhaki, S. (1974). A note on "Income tax evasion: A theoretical analysis". Journal of Public Economics, 3 (2), 201-202. 


\section{Box 1: Measuring tax evasion - Three case studies}

1. Measuring evasion via the shadow economy

As typically defined, the shadow economy is clearly not synonymous with tax evasion. Even so, researchers often use shadow economy estimates to proxy the amount of tax evasion. Alm and Embaye (2010) apply the currency demand approach to estimate the shadow economy for 108 countries for the years 1984-2006, using panel data estimation methods. Their results indicate a clear growth in the average size of the shadow economy over time, and a clear tendency for the shadow economy to be larger for lower income countries. For example, they estimate that the average size (unweighted) of the shadow economy across all countries and all years is 32.5 percent of GDP, but that the estimated size is 47.7 percent of GDP for "low income" countries, 36.7 percent for "lower middle income" countries, 25.9 percent for "upper middle income" countries, 16.2 percent for "high income, non-OECD" countries, and 14.7 percent for "OECD" countries. These numbers parallel those of Schneider (2005), with some exceptions.

\section{Measuring income tax evasion via nonfiling}

As part of tax reform project in Jamaica in the mid-1980s, Alm, Bahl, and Murray (1991) needed to estimate the amount of tax evasion from nonfiling of individual income tax returns. They started by compiling a master list of 29,838 names from third-party sources of information (e.g., telephone directories, trade association lists), from which they selected 12,336 names (for service stations, customs brokerages, auto repair, auto parts, hair care, real estate, contractors, transport, and beverage and spirits). They took these names to the Jamaica Income Tax Department to determine whether these individuals filed a return (or had income taxes withheld). Their findings were striking: only 10.9 percent filed a return. Assuming that the characteristics of those who filed were the same as those who did not file, they estimated that the amount of undeclared income was 28.0 percent of reported income, costing the government 38.8 percent of actual income taxes collected in 1984. They also repeated this analysis for "professionals" (e.g., accountants, architects, attorneys, doctors, optometrists, and veterinarians), and found a filing rate of only 22.6 percent.

3. Measuring online seller evasion via internet transactions

The growth of online commerce has eroded state sales tax bases, given that out-of-state vendors are not required to collect sales taxes in states where they have no legal presence. However, the extent of this sales tax evasion by online sellers remains quite speculative. Alm and Melnik (2010) their own data from eBay.com on a "representative" commodity classification and a "typical" day - all "Consumer Electronics" sold on eBay over a 24-hour period in summer 2007 - consisting of twenty-two thousand eBay listings generated by seven thousand individual sellers with ninety-three hundred buyers. They were able to observe whether the seller collected sales taxes, and they used this information to answer three questions. First, how many sellers actually collect state sales taxes? Second, what is the revenue loss from the seller noncompliance? Third, is seller noncompliance related to specific factors, like seller characteristics or the level of state sales tax rates? They found that overall eBay seller compliance is quite low (around 18 percent), but that compliance by larger, established sellers is significantly higher (roughly 50 percent). Given that established sellers account for the bulk of online commerce, the estimated revenue loss from seller noncompliance is relatively small. A driving force is cross-border transactions. More recent estimates using the same data indicate that online buyer compliance with state use taxes is virtually zero. 


\section{Box 2: Explaining tax evasion - Three case studies}

1. Using theory: Taxpayer uncertainty and tax evasion.

Alm (1988) examines how individuals respond to greater uncertainty about individual income taxes. One type of uncertainty that he examines is "tax base risk", where the individual does not know with certainty whether the government will change the basic nature of the tax base. In the context of tax evasion, tax base risk is modeled by assuming that the fraction of underreported income that is detected by the authorities with an audit is a random variable, and greater uncertainty is introduced as a mean-preserving spread in the distribution of this risky parameter. Alm (1988) finds that under some plausible restrictions on individual preferences - restrictions that ensure that the substitution effect of greater risk exceeds the income effect - an individual responds to increased tax base risk by increasing the amount of reported income; that is, greater taxpayer uncertainty about the fraction of income that is discovered in an audit generally increases reported income. He concludes that the deliberate introduction of such uncertainty may actually benefit a government that is only interested in generating more tax revenues. He also shows that, if the government is allowed to reduce tax rates to keep expected revenues constant in the face of greater tax base risk, there are plausible circumstances under which taxpayer welfare increases, despite the presence of greater tax base uncertainty.

2. Using empirical methods: Spatiality and persistence in tax compliance.

Alm and Yunus (2009) use U.S. state-level, time-series, cross-section data for the years 1979 to 1997 to estimate the factors that affect per return evasion of the individual income tax, focusing on the twin issues of spatiality and persistence in the individual income tax evasion decision: the issue of persistence arises through accumulated learning over time, while spatiality arises from the exchange of information between taxpayers, the social norm of tax compliance, and the difficulties faced by individuals with dynamic stochastic decision problems like tax evasion. Their estimation methods incorporate both spatial dependence and dynamic considerations. (They also consider the potential endogeneity of the audit rate.) Their empirical results provide strong and robust support for both spatiality and persistence in tax evasion. Their results also show a large deterrent effect from higher audit rates.

\section{Using experiments: The external validity of experiments.}

A common criticism of experimental economics is the use of student subjects, on the grounds that student responses may not be representative of the general taxpaying public. Alm, Bloomquist, and McKee (2010) examine this issue of the "external validity" of experimental results by comparing student responses in experiments with non-student, non-experimental responses based on data from the National Research Program (NRP). They first compare student responses to non-student responses in identical experiments, in an attempt to answer the question: do students behave differently than non-students in the same experiments? They also compare student/experimental results with non-student, non-experimental results in a "similar" setting, where non-student/nonexperimental responses are based on data from the NRP; that is, do students in experiments behave differently than non-students in naturally occurring settings? Finally, they compare non-student responses in experiments with non-student responses in NRP data: do non-students behave differently in experiments versus the naturally occurring world? They find no significant differences in mean compliance rates, in the distribution of compliance rates, or in econometrically estimated behavioral responses between students and non-students, whether in experiments or in NRP data. 


\section{Box 3: Controlling tax evasion - Three case studies}

\section{Using enforcement: The "enforcement paradigm"}

How are an individual's compliance decisions affected by enforcement (and other fiscal) parameters? Alm, Bahl, and Murray (1990) develop a model in which individuals choose the shares of compensation received in the form of reported taxable compensation, evasion income, and avoidance income, as a function of the probability of detection, the penalty on unpaid taxes, the marginal income and payroll tax rate, and payroll tax benefits. They then estimate the resulting share demand equations using a unique data set on the compensation paid to roughly one-quarter of the formal labor force in Jamaica in 1983, data that allow them to derive individual measures of reported taxable income, evasion income, and avoidance income. Their estimation results indicate that the reported tax base falls with more severe penalties and more certain detection of evasion as individuals substitute towards avoidance income; the tax base also rises with higher benefits for payroll tax contributions and falls with higher marginal tax rates. The estimated tax base elasticities indicate that enforcement (and other fiscal variables) matter, even though the responses are generally small. The penalty elasticity is -0.08 , and the probability elasticity is even smaller $(-0.01)$. The largest response stems from an increase in the marginal tax rate $(-0.19)$, and the payroll benefits elasticity is 0.07. The interrelationships among compensation types also indicate that policy cannot be used in isolation to influence the choice of one compensation type unless the implications for other forms of compensation are considered.

\section{Providing services: The "service paradigm"}

How are an individual's filing and subsequent reporting decisions affected by tax agency provision of information, in an environment in which individuals do not know with certainty their true tax liability; that is, do "services" improve compliance? Alm, Cherry, Jones, and McKee (2010) use experimental methods where subjects receive income, they must choose whether or not to file a tax return, they pay taxes on income voluntarily reported, and they face some chance that underreported taxes will be detected and penalized. This process is then "complicated" by introducing uncertainty about the individual's "true" tax liability, and then the "tax administration" provides "services" that allow subjects to compute more easily their tax liabilities. Alm, Cherry, Jones, and McKee (2010) find that individuals report roughly 14 percent less income when their tax liability is uncertain. However, this lower reporting is more than offset when the tax agency provides services to the taxpayer, thereby increasing reported income by nearly 20 percent. Their results indicate clearly that strategies to improve compliance must be based on improved enforcement but also on an approach that emphasizes other administrative policies such as services.

\section{Changing the culture: The "trust paradigm"}

How are an individual's reporting decisions affected by group choice of the use of taxes? Alm, Jackson, and McKee (1993) use experimental methods, starting with the standard experimental design: individuals receive income, pay taxes on income voluntarily reported, and face some chance that underreported taxes will be detected and penalized. They then extend the design by introducing elements of social interactions and fiscal exchange. In some treatments subjects must choose among two alternative types of public goods, with the type of public good decided by majority vote; in other treatments, the subjects are not allowed to vote on public good provision, and the public good is instead imposed on the group. The level of support for the public good alternatives also varies. In some treatments group members strongly prefer one of the alternative public good types; the level of support for the two alternatives is more evenly divided in other treatments. Their results indicate that both the manner in which group decisions are made and the level of popular support for the public goods over which these other dimensions of public good provision affect compliance. Compliance is significantly higher when individuals vote on the use of their taxes than when the identical result is imposed upon them. Compliance is also higher when the vote is decisive than when the vote is close. Finally, compliance is significantly lowered by the imposition of an unpopular expenditure program; indeed, compliance is lower with an imposed and unpopular public good than in the complete absence of any public good. These results suggest that government can increase compliance by ensuring that individuals feel that they have a say in the manner in which their taxes are spent, that citizens are well informed of the outcome of the vote, and that citizens trust that taxes will be spent in ways consistent with their wishes. 